\title{
Ocorrência de Carollia castanea na Amazônia Brasileira \\ (Chiroptera, Phyllostomidae)
}

\author{
Wilson Uieda \\ Universidade Estadual de Compinos \\ Bolsista do CNPq.
}

Em sua revisão do gênero Carollia, Pine (1972) reconheceu quatro espécies: C. perspicillata (Linnaeus, 1758); C. brevicauda (Schinz, 1821); C. castanea H. Allen, 1890; C. subrufa (Hahn, 1905). Com exceção de C. subrufa estas espécies ocorrem na América do Sul (Pine, 1972). C. castanea foi registrada para
Venezuela, Colômbia, Equador, Peru e Bolívia (Pine, 1972); Handley, 1976; Koopman, 1978). A presente nota é o primeiro registro desta espécie para o Brasil.

Tive oportunidade de examinar uma fêmea de Carollia castanea, coletada por Emílio Dente em 21 de março de 1979, na fazenda São 
José, rio Peixoto de Azevedo, Chapada dos Guimarães, Mato Grosso (aprox. 1'15'S, $54^{\circ} 50^{\prime} \mathrm{W}$ ). O animal fol capturado em rede de espera ("mist net"), armada em floresta primária, a cerca de $400 \mathrm{~m}$ de altitude. O exemplar, conservado em álcool, foi depositado na coleção do Departamento de Zoologia, Universidade Estadual de Campinas (ZUEC 1018). Miedidas externas e cranianas foram tomadas de acordo com o critério de Pine (1972). O tubo digestivo foi extraído para análise do seu conteúdo.

O espécime aqui estudado apresenta as seguintes medidas $(\mathrm{mm})$ : antebraço, 34,9 ; tíbia, 14,3; comprimento do crânio, 19,5; comprimento côndilo-incisivo, 16,8; comprimento palatal, 8,4; largura da caixa craniana, 8,6; comprimento da série de dentes superiores, 6,2; comprimento da série de dentes inferiores, 6,7; comprimento da mandíbula, 12,9.

O exemplar de Carollia castanea, do rio Peixoto de Azevedo, concorda bem com a descrição da espécie apresentada por Pine (1972), em sua revisão do gênero. Segundo o autor citado, esta espécie é a menor forma de Carollia e com caracteres mais divergentes, sendo facilmente reconhecida. Não encontrei maiores dificuldades em identificar o espécime aqui referido, de acordo com o critério usado por Pine (1972). Koopman (1978) já havia assinalado a relativa facilidade para identificar C. castanea, ao trabalhar com espécimes do Peru.

Na América do Sul, Carollia castanea está praticamente confinada às regiões de baixa altitude da Amazônia (Koopman, 1978), ocorrendo principalmente em floresta perenifolia (Pine, 1972; Handley, 1976). A sua ocorrência na Amazônia brasileira podia ser prevista, uma vez que fora assinalada na parte amazônica de países vizinhos (Venezuela, Colômbia, Peru e Bolívia). Apesar de Husson (1962; 1978) ter assinalado C. castanea para o Suriname, Genoways \& Williams (1979) sugerem um estudo mais apurado dos dois espécimes referidos por Husson, para melhores esclarecimentos acerca da sua identidade. As medidas destes espécimes são muito similares às cie C. brevicauda, que também ocorre no Suriname (Genoways \& Williams, 1979). Aparentemente, o rio Peixoto de Azevedo é a ocorrência mais ocidental registrada para C. castanea.

O tubo digestivo do exemplar examinado estava praticamente vazio, restando somente resíduos aderidos às paredes do estômago, intestino e reto; desse material, reconheci apenas fibras vegetais. Howell \& Burch (1974), ao examinar espécimes de C. castanea coletados em maio na Costa Rica, encontraram somente frutos de Piper spp. (Piperaceae) no seu tubo digestivo. Gardner (1977) comentou que esta espécie de morcego se alimenta de frutos e insetos. Pouco se conhece sobre os hábitos alimentares das diversas espécies de Carollia, com exceção de C. perspicillata, comum e muito estudada (veja Heithaus et al., 1975; Fleming et al., 1977; Heithaus \& Fieming, 1978). Apesar da revisão do gênero (Pine, 1972), vários autores têm confundido as quatro espécies reconhecidas por Pine, fato que dificulta um melhor conhecimento dos hábitos alimentares de cada uma delas (Gardner, 1977).

Com o presente registro, as espécies de Carollia que ocorrem no Brasil são C. perspicillata, C. brevicauda e C. castanea, "sensu" Pine (1972).

\section{SUMMARY}

The present note is the first record of the fruiteating bat, Carollia castanet, for Brazil. The bat, an aduli female, was collected at the rio Peixoto de Azevedo, Chapada dos Guimarăes, state of Mato Grosso. Apparently, the rio Peixoto de Azevedo is the easternmost locality recorded for C. castanea.

\section{BIBLIOGRAFIA}

Fieming, THeodore H.; HeIthaus, E. Raymond \& S.MYER, WHLLAM B.

1977 - An experimental analysis of the food location behavior of frugivorous bats. Ecology, 58 (3): 619-627.

GARDNER, ALFRED L.

1977 - Feeding habits, In Baker, Robert J.; Jones, Jr., J. Knox \& Carter, Dilford C. Biology of bats of the New World family Phyllostoma. tidae. Part II. Spec. Publ. Mus., Texas Tech Univ., 13 293-350. 
Genoways, Hugh H. \& WILliams, Stephen L.

1979 - Records of bats (Mammalia: Chiroptera) from Suriname. Ann. Carnegie Mus., 48 (18): 323-335.

Hindeey, Charles O., JR.

1976 - Mammals of the Smithsonian Venezuelan Project. Brigham Young Univ. Sci. Bull., biol. ser., 20: 1-91.

Hetthaus, E. RAymond; Fleming, Theodore H. \& OPLER, PAUL A.

$$
\begin{aligned}
& 1975 \text { - Foraging patterns and resource utilization } \\
& \text { in seven species of bats in a seasonal tro- } \\
& \text { plcal forest. Ecology, } 56 \text { (4): } 841-854 \text {. }
\end{aligned}
$$

Heithaus, E. RAymond \& Fleming, Theodore H.

1978 - Foraging movements of a frugivorous bat, Carollia perspicillata (Phyllostomatidae). Ecological Monographs, 48 (2): 127-143.
Howell, Donna J. \& Burch, Derex

1974 - Food habits of some Costa Rican bats. Rev. Biol. Trop., 21 (2): 281-294.

Husson, ANTONius M.

1962 - The bats of Suriname. Zool. Verhand., 58: 1-282.

1978 - The mammals of Suriname. Zool. Monogr., Rijksmus. Nat. His., 2: $1-569$.

KOOPMAN, KARL F.

1978 - Zoogeography of Peruvian bats with special emphasis on the role of the Andes. Amer. Mus. Novitates, 2651: 1-33.

PINE, RONALD H.

1972 - The bats of the genus Carollia. Texas A \& M Univ., Texas Agri. Exp. Sta., Tech. Monogr., 8: 1-125.

(Aceito para publicação em 11/08/80) 